\title{
Aplikasi Aktuator Pneumatik sebagai Simulator Beban Dinamis Vertikal pada Mekanisme Suspensi Roda Kendaraan Seperempat
}

\author{
Simon Ka'ka,a, Syukri Himran ${ }^{2}$, Ilyas Renreng ${ }^{2}$ dan Onny Sutresman ${ }^{2}$ \\ ${ }^{1}$ Jurusan Teknik Mesin, Politeknik Negeri Ujung Pandang, Sulawesi Selatan 90245, Indonesia \\ ${ }^{2}$ Jurusan Teknik Mesin, Fakultas Teknik, Universitas Hasanuddin, Sulawesi Selatan 90245, Indonesia \\ asimon_kaka@poliupg.ac.id
}

\begin{abstract}
Driving comfort for riders and passengers is a key target to be achieved. Fluctuations in vehicle loads, bumps, perforated surfaces, and other road damage will greatly affect the vehicle suspension working system. This study aims to calculate the vertical dynamic load of the vehicle actually which occurs on road construction after through the vehicle wheel suspension mechanism. The Pneumatic cylinder that was driven by pressurized air directly weigh on the spring and Shock Absorber that contained on the wheels of the vehicle. The load fluctuations of the medium weight category vehicle are determined by the regulation of the amount of pressurized air entering into the pneumatic cylinder chamber pushing the piston and connecting rods. The deviation that occurs during compression on the Spring and Shock Absorber, is substituted into the vehicle dynamic load equation by taking also the magnitude of the spring stiffness constant, and the fluid or gas coefficient of the damper. The results showed that the magnitude of the displacement when the compression force worked has significantly influenced the amount of vertical dynamic load of the vehicle that overlies the road construction. Experimental results using pneumatic actuators instead of real dynamic vehicle loads illustrate the characteristics of the relationship between work pressure and dynamic load. If the working pressure of $\mathbf{P}_{2}$ (bar) is given great, the vertical dynamic load $\mathrm{Ft}(\mathrm{N})$ which overloads the structure of the road is also greater. From the graph shows that shock absorbers have greater ability to reduce dynamic load vertically when compared to spring ability.
\end{abstract}

Keywords- Dynamic load; Pneumatic Cylinder; Pressurized air; Suspension; and Road

\footnotetext{
Abstrak - Kenyamanan berkendara oleh para pengemudi merupakan suatu target utama yang ingin dicapai. Fluktuasi beban-beban kendaraan,gundukan-gundukan, serta kerusakan jalan lainnya akan berpengaruh besar terhadap sistem kerja suspense kendaraan. Penelitian ini bertujuan untuk menghitung besarnya beban dinamis vertikal kendaraan sesungguhnya terjadi pada kontruksi jalan setelah melalui mekanisme suspensi
}

roda kendaraan. Silinder Pneumatik yang digerakkan oleh udara bertekanan membebani langsung pegas dan Shock Absorber yang terdapat pada roda kendaraan. Fluktuasi beban dari kendaraan kategori bobot sedang ditentukan oleh pengaturan besarnya udara bertekanan masuk ke dalam ruang silinder pneumatik mendorong torak dan batang penghubung. Simpangan yang terjadi pada saat kompressi pada Pegas dan Shock Absorber, disubstitusi ke dalam persamaan beban dinamis kendaraan dengan memperhitungkan pula besarnya konstanta kekakuan pegas, dan koefisien cairan atau gas peredam. Hasil penelitian menunjukkan bahwa besarnya perpindahan saat gaya kompressi bekerja telah memberikan pengaruh secara signifikan terhadap besarnya beban dinamis vertikal kendaraan yang membebani konstruksi jalan. Terdapatnya beban dinamis kendaraan yang berfluktuasi dan berulang, juga berdampak pada berkurangnya kemampuan jalan menerima beban. Hasil eksperimen yang menggunakan actuator pneumatic sebagai pengganti beban dinamis nyata kendaraan memberikan gambaran karakteristik hubungan antara tekanan kerja dan beban dinamis. Jika tekanan kerja $P_{2}$ (bar) yang diberikan semakin besar, maka beban dinamis vertikal $\mathrm{Ft}(\mathrm{N})$ yang membebani struktur jalan semakin besar pula. Dari grafik menunjukkan bahwa shock absorbermemiliki kemampuan lebih besar meredam beban dinamis vertikal apabila dibandingkan dengan kemampuan pegas.

Kata Kunci-Beban dinamis; Silinder Pneumatik; Udara bertekanan; Suspensi; dan Jalan

\section{Pendahuluan}

Sejumlah jenis kendaraan roda empat atau lebih yang melints di atas permukaan jalan raya setiap saat menghasilkan sejumlah beban dinamis yang fluktuatif. Pembebanan yang fluktuatif ini selain diperoleh dari variasi beban dinamis,VBD dapat pula disebabkan oleh adanya beban lebih (overload, OL)dan beban berulang 
(Repetition loads,RL)[1]. Efek dari transfer beban fluktuatif (BF), beban lebih OL dan beban berulang RL akan menurunkan kemampuan/stabilitas struktur jalan dalam bentuk deformasi permukaan yang berlubang atau bergelombang. Kemampuan struktur jalan menerima beban dinamis vertikal kendaraan tersebut adalah tergantung pada jenis lapisan permukaan, lapisan pondasi elastis dan lapisan pondasi geser.

Variasi bobot kendaraan ringan, sedang dan berat yang melintas di atas permukaan jalan secara simultan akan sangat mempengaruhi kemampuan lapisan pondasi elastis jalan menerima beban tersebut. Berdasarkan permasalahan tersebut maka diperlukan kajian terhadap beberapa variabel yang berpengaruh baik yang sifatnya langsung maupun tak langsung. Pembebanan fluktuatif dipengaruhi oleh variabel berat sumbu roda dan berat kendaraan. Kondisi pembebanan berulang RL adalah juga sangat dipengaruhi oleh arus pengulangan lalulintas, volume rerata arus lalu lintas (Jumlah.kend./jam) yang dihasilkan oleh setiap jenis kendaraan serta lamanya kendaraan melintas.

Suatu upaya yang dilakukan untuk mengkaji beban dinamis dari kendaraan kategori bobot sedang yang melintas di jalan maka diperlukan sebuah eksperimen terhadap pembebanan seperempat bagian kendaraan yang berpusat pada sebuah roda depan kendaraan. Kajian yang inovatif ini didasarkan pada pengetahuan dasar tentang mekanisme transfer pembebanan vertikal melalui sistem suspensi roda yang terdiri atas kerja pegas dan shock absorber.

Kajian tentang beban dinamis yang ditranformasikan melalui mekanisme kerja suspensi pada roda kendaraan terhadap jalan adalah (1) bertujuan untuk mengetahui bentuk formula dan besarnya beban dinamis vertikal dari setiap jenis bobot kendaraan sedang yang melintas, (2) mengetahui karakteristik kemampuan jalan menerima beban berulang RL dan beban lebih OL serta (3) menghasilkan suatu nilai konstanta hubungan/perbandingan antara beban dinamis vertikal kendaraan dan kemampuan jalan dalam bentuk parameter tak berdimensi.

Sebuah unsur kebaruan yang ditargetkan dalam penelitian ini adalah memanfaatkan aktuator pneumatik pada alat uji/eksperimen sebagai pengganti beban dinamis kendaraan membebani permukaan jalan. Udara bertekanan dari kompresor memberikan gaya tekan kompresi secara bervariasi terhadap pegas dan shock absorber yang terdapat pada sistem suspensi.

Mekanisme suspensi pasif dan kondisi struktur pembebanan seperempat kendaraan ditunjukkan pada gambar 2.4.[2, 3]. Berat badan kendaraan (mass sprung) $\mathrm{m}_{2}$ dengan kekakuan pegas $\mathrm{k}_{2}$ dan koefisien redaman $\mathrm{c}$ akan membebani poros roda kendaraan (mass unsprung) $\mathrm{m}_{1}$ selanjutnya memberikan gaya aksi terhadap kontur permukaan jalan.

Untuk kendaraan kategori ringan: memiliki beban sumbu $\mathrm{m}_{1}=400 \mathrm{~kg}$, dan berat kendaraan, $\mathrm{m}_{2}=835$ sampai $1394 \mathrm{~kg}$. Kendaraan kategori sedang: memiliki beban sumbu, $\mathrm{m}_{1}=480$ sampai $600 \mathrm{~kg}$ dan berat kendaraan, $\mathrm{m}_{2}$ $=1185$ sampai $1990 \mathrm{~kg}$. Sedangkan kendaraan kategori berat: memiliki beban sumbu, $\mathrm{m}_{1}=525$ sampai $850 \mathrm{~kg}$, dan berat badan kendaraan, $\mathrm{m}_{2}=5200$ sampai $8730 \mathrm{~kg}$ (sumber: P.T. Astra Internasional, 2014, Lampiran 1). Kondisi pembebanan lebih OL, tergantung pada nilai konstanta $\boldsymbol{k}$ dan beban sumbu $\boldsymbol{m}_{\boldsymbol{1}} \sim \boldsymbol{L}$ (kg, ton) untuk setiap jenis kendaraan. Besarnya nilai $\mathrm{k}$ untuk sumbu tunggal: $\mathrm{k}=1$, sumbu ganda: $\mathrm{k}=0.086$ dan sumbu triple: $\mathrm{k}=0.031$.
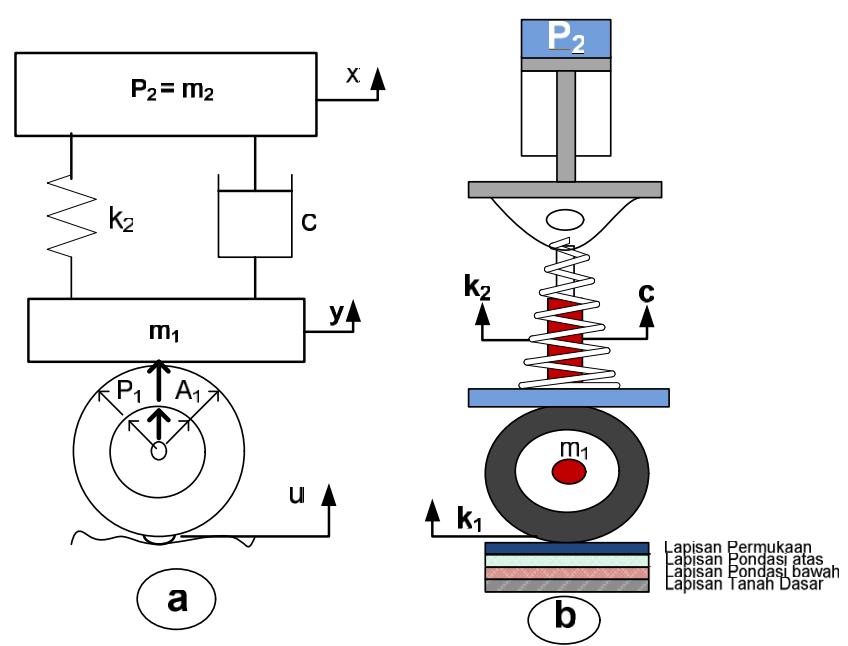

Gambar 1. (a) Model suspensi pasif (b) Unit suspensi, shock absorber,sumbu dan roda pada struktur lapisan jalan.

Gaya reaksi dari kontur jalan terhadap ban akan terdistribusi dalam arah $\mathrm{u}$ melalui konstanta elastisitas ban $\boldsymbol{k}_{\boldsymbol{l}}$. Besarnya gaya dinamis vertikal oleh aktuator pneumatik ekivalen pada gaya berat badan kendaraan (2) adalah dijelaskan pada persamaan (2.5). Simpangan kompressi sejauh $\mathrm{x}_{2}(\mathrm{~cm})$ akan bervariasi sesuai dengan 
besarnya tekanan kerja $\mathrm{P}_{2}$ (bar) yang divariasikan mulai dari 1 bar sampai 8 bar.

$$
\left.\begin{array}{c}
F_{p 2}=F_{a f}=F_{k}-R_{f}=F_{k}-0.1 F_{k}=0.9 F_{k} \\
\sum F_{v-0} \\
F_{a f}-\left(F_{k 2}+F_{c 2}\right)=0 \\
0.9 F_{k}-\left(k_{2}+c\right) x_{2}=0 \\
F_{k}=\frac{\left(k_{2}+c\right) x_{2}}{0.9} \\
F_{p 2}=F_{k}=1.1\left(k_{2}+c\right) x_{2}
\end{array}\right\}
$$

Jika gaya $\mathrm{N}$ bekerja bersama-sama dengan gaya berat sumbu pada roda (1) maka diperoleh hubungan:

$$
\left.\begin{array}{c}
F_{t 1}=F_{p 2}+F_{r 1} \\
F_{t 1}=0.9 F_{k}+\left(m_{1} \cdot g\right)
\end{array}\right\}
$$

Apabila diameter torak, $\mathrm{D}=100 \mathrm{~mm}(0.100 \mathrm{~m}), \mathrm{k}_{2}=$ konstanta pegas, $\mathrm{c}=$ koefisien redaman, $\mathrm{m}_{1}=$ berat sumbu roda, percepatan gravitasi $\mathrm{g}=10 \mathrm{~m} / \mathrm{s}^{2}$ dan gaya dorong torak silinder pneumatik, $\mathrm{F}_{\mathrm{k}}=\pi / 4\left(\mathrm{D}^{2}\right) \mathrm{P}_{2}$, maka persamaan (2) menjadi:

$$
F_{\mathrm{t} 1}=785 P_{2}+10 m_{1}(\mathrm{~N})
$$

Gaya efektif $\mathbf{F}_{\text {ef }}(\mathrm{N})$ torak silinder pada langkah maju adalah selisih antara gaya teoritis, $\mathbf{F}_{\mathbf{k}}(\mathrm{N})$ dan gaya gesek $\mathbf{R}_{\mathbf{f}}(\mathrm{N})$ [4]. Jika gaya gesek $\mathbf{R}_{\mathbf{f}}$ ditetapkan sebesar $10 \% \times \mathrm{F}_{\mathrm{k}}(\mathrm{N})$ maka secara keseluruhan mekanisme transfer beban terhadap struktur jalan aspal adalah mengacu pada Diagram Benda Bebas (DBB) berikut:

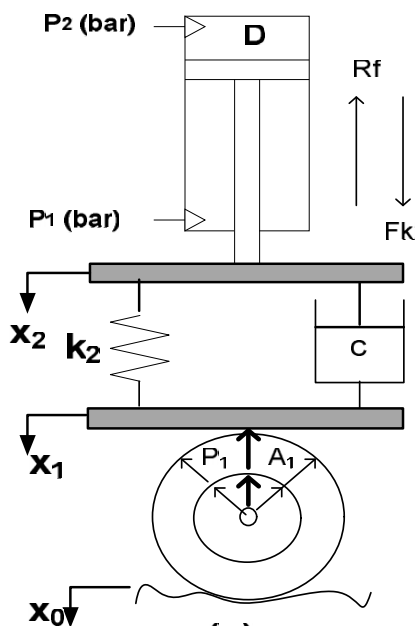

(a)

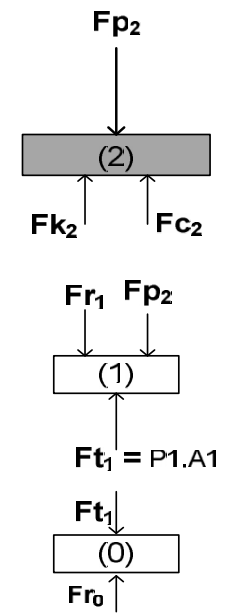

(b)
Gambar 2. Mekanisme pembebanan ekperimental sistem pneumatik
Jika pegas dan shock absorber mengalami pembebanan bervariasi dari tekanan $\mathrm{P}=1$ sampai 8 bar, maka akan terjadi simpangan ke arah kompressi sejauh $\mathrm{x}(\mathrm{mm})$. Berdasarkan hukum aksi-reaksi, menjelaskan bahwa beban yang diberikan pada pegas adalah sebanding dengan besarnya lendutan dikali dengan konstanta pegas. Besarnya perpindahan (displacement) rata-rata pada sistem suspensi hasil optimasi $\mathrm{x}=0.009264 \mathrm{~m}$ dengan percepatan vertikal maksimum adalah $15.5707 \mathrm{~m} / \mathrm{s}^{2}$. Pada kondisi ini diperoleh nilai koefisien kekakuan pegas suspensi $\mathbf{k}_{\mathbf{s}}=41821 \mathrm{~N} / \mathrm{m}$, serta koefisien peredam suspensi $\mathbf{c}_{\mathbf{s}}$ $=68574 \mathrm{~N} . \mathrm{s} / \mathrm{m}$ [5] serta cs $=1920 \mathrm{~J} / \mathrm{kg} . \mathrm{K}$ [6]. Prototipe suspensi yang diuji oleh [7] mempunyai data konstanta pegas $\boldsymbol{k}_{\boldsymbol{s}}=10581,292 \mathrm{~N} / \mathrm{m}$, koefisien redaman kejut, $\boldsymbol{c}_{\boldsymbol{s}}=96,073$ Ns/m dan konstanta elastis ban, $\mathbf{k}_{\boldsymbol{e}}=98041,246 \mathrm{~N} / \mathrm{m}$. Kajian tentang hubungan antara diameter piston $\mathrm{D}$ dengan diameter lubang saluran $\mathrm{d}_{\mathrm{i}}$ telah dilakukan studi pendahuluan $[8,9]$ dalam bentuk persamaan (4).

$$
d_{\mathrm{i}}=0.065713 \mathrm{D}
$$

Dimensi saluran udara yang akan digunakan adalah disesuaikan dengan dimensi piston silinder pneumatik yang dipilih.

Berdasarkan spesifikasi ban/roda untuk kendaraan ringan dan kendaraan sedang digunakan tekanan standar tekanan angin dalam ban sebesar 2 bar,dan 5.86 bar untuk kendaraan berat. Jika ukuran ban/roda yang digunakan berdimensi: 215/60/16 yang berarti, lebar ban $\mathrm{S}=215 \mathrm{~mm}$, tinggi $\mathrm{T}=60 \% \mathrm{xS}(\mathrm{mm})=129$ $\mathrm{mm}=0.129 \mathrm{~m}$, dan Diameter roda, $\mathrm{D}_{1}=16$ "(inches) $=$ $16 \times 25 \mathrm{~mm}=400 \mathrm{~mm}=0.4 \mathrm{~m}$, dan tekanan udara dalam ban $\mathrm{P}_{1}=2$ bar $=200000 \mathrm{~N} / \mathrm{m}^{2}$, dan luasan ban

$$
\begin{aligned}
& A_{1}=\pi\left[r_{o}^{2}-r_{i}^{2}\right]=3.14\left[0.102^{2}-0.020^{2}\right]= \\
& 0.031412 \mathrm{~m}^{2},
\end{aligned}
$$

maka gaya inner ban/roda menahan beban vertikal kendaraan adalah $\mathrm{Ft}_{1}=\mathrm{P}_{1} \times \mathrm{A}_{1}=6282.4 \mathrm{~N}$.

Besarnya koefisien beban dinamis kendaraan dirumuskan [10] sebagai perbandingan antara beban dinamis rata-rata dengan beban statis sebagai berikut:

$$
D L C=\frac{\text { Reratabebandinamis }}{\text { Beban statis }}=\frac{F D_{r m s}}{F_{g}}
$$

Untuk kendaraan dengan suspensi hydro-pneumatic maka beban dinamis dapat berkurang sebesar $20 \%$. Pada kondisi tersebut Dynamic Load Coeficient (DLC) 
menjadi, $\quad D L C=\frac{(100-20) \%}{100 \%}=0.80$. Apabila roda kendaraan $1 / 4$ sedang menggelinding di atas permukaan jalan, maka beban dinamis vertikal kendaraan diformulasikan sebagai berikut:

$$
\left.\begin{array}{c}
F_{D V}=0.8 x F_{t 1} \\
=628 P_{2}+8 m_{1} \leq F_{A 0}
\end{array}\right\}
$$

\section{Metode Penelitian}

\section{A. Eksperimen}

Secara eksperimen pembebanan terhadap struktur pondasi jalan dilakukan dengan mengekuivalenkan berat total badan kendaraan $m_{l}(\mathrm{~kg})$ dan bobot sumbu roda $m_{2}$ $(\mathrm{kg})$, dengan gaya dorong torak silinder pneumatik, $\mathbf{F}_{\text {ef. }}$ (N) sebagai aktuator bekerja pada tekanan kerja $\mathrm{P}_{2}=1$ sampai 8 (bar). Penelitian yang berorientasi pada simulasi gaya piston silinder pneumatik yang diidentikkan sebagai beban dinamis nyata kendaraan ditunjukkan pada gambar 3. Jika gaya tekan dari torak silinder pneumatik menekan pegas dan shock Absorber maka akan terjadi proses kompressi yang ditandai oleh penunjukan jarum x pada skala perpindahan ( $\mathrm{mm})$.

\section{B. Pengumpulan Data}

Berdasarkan pada simulasi pembebanan, maka pengumpulan data-data eksperimen dilakukan dengan membaca skala (11) penunjukan jarum /dial indikator perpindahan, $x(\mathrm{~mm})$ sesaat terjadi kompressi pada pegas (10). Besarnya perubahan perpindahan yang terjadi adalah sangat ditentukan oleh besarnya tekanan udara $P_{2}$ (bar) yang diatur mulai dari 1 (bar) sampai 8 (bar). Agar supaya hasil pengukuran $\mathrm{x} \mathrm{mm}$ dapat lebih mendekati keadaan nyata maka perlu dilakukan pengukuran $\mathrm{x}(\mathrm{mm})$ sampai 5 kali pada setiap pengaturan tekanan kerja dengan mengitung harga $\mathrm{x}$ $(\mathrm{mm})$ rerata.

Kecepatan aliran fluida kerja masuk ke dalam silinder menurut [11] adalah sangat memberikan suatu pengaruh secara signifikan terhadap gaya pada suspensi kendaraan.

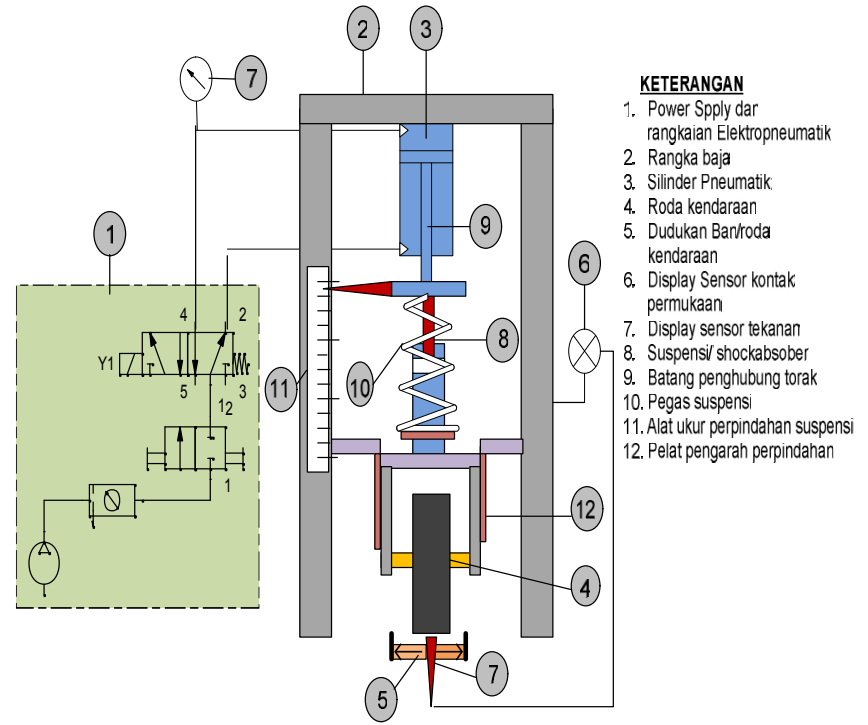

Gambar 3. Simulasi pembebanan dengan aktuator pneumatik

\section{Analisis Data}

Besarnya perpindahan rerata $\mathrm{x}(\mathrm{mm})$ yang diperoleh tersebut selanjutnya disubstitusi ke persamaan (1) dan (4) sebagai gaya berat badan kendaraan, $F p_{2}(\mathrm{~N})$ dan gaya dinamis vertikal nyata kendaraan, $F t_{1}(\mathrm{~N})$ terhadap konstruksi jalan. Dengan bantuan analisis program MatLab/Simulink, maka besarnya $F p_{2}(\mathrm{~N})$ dan, $F t_{1}(\mathrm{~N})$ dapat diperoleh, serta karakteristik pembebanan yang dilakukan terhadap konstruksi jalan dapat ditunjukkan melalui gambar grafik.

\section{Hasil dan Pembahasan}

Simulasi beban dinamis kendaraan yang diperankan oleh silinder/aktuator pneumatik menghasilkan besarnya beban dinamis kendaraan membebani struktur jalan dengan mengacu pada persamaan (3). Jika tekanan kerja, $\mathrm{P}_{2}$ sebagai pengganti beban $\mathrm{m}_{2}$ divariasikan dari 1 bar sampai 8 bar, maka karakteristik kerja beban dinamis terhadap tekanan kerja ditunjukkan pada Gambar 4.

Grafik hubungan antara tekanan kerja P2 (bar) dan Beban dinamis vertikal membebani struktur jalan menggambarkan kenaikan beban dinamis secara signifikan dengan kenaikan beban total kendaraan. Kondisi signifikansi ini diperlihatkan dalam gambar grafik sebagai garis lurus. 


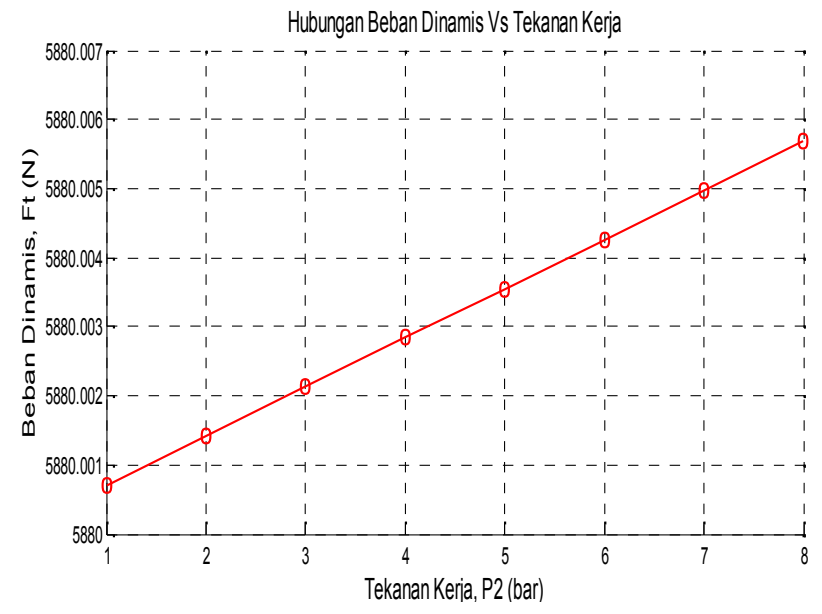

Gambar 4. Karakteristik Beban Dinamis sistem pneumatik

Karakteristik beban dinamis yang diperoleh dari hubungan antara tekanan operasi dengan konstanta pegas $\mathrm{k}_{2}$, Gaya tekan piston silinder pneumatik, $\mathrm{Fp}_{2}$, redaman shock absorber $\mathrm{c}_{2}$ serta besarnya beban dinamis vertikal yang membebani struktur jalan $\mathrm{Ft}_{1}$ ditunjukkan pada Gambar 5(a). Pengaruh redaman oleh shock absorber memberikan pengaruh yang sangat besar terhadap beban dinamis kendaraan membebani struktur jalan. Kondisi yang demikian menyebabkan besarnya beban dinamis $\mathrm{Ft}_{1}(\mathrm{~N})$ menurut Gambar 5 (b) berada disekitar 10000 $(\mathrm{N})$ atau eqivalen dengan $1000 \mathrm{~kg}$.

Jadi jika kendaraan kategori bobot sedang yang diuji memiliki bobot sumbu roda $\mathrm{m}_{1}=600 \mathrm{~kg}$, bobot badan $\mathrm{m}_{2}=1665 \mathrm{~kg}$ dan bobot total $/$ net $\mathrm{m}_{\mathrm{t}}=2265 \mathrm{~kg}$ sesuai data dalam Tabel 1 maka diperoleh beban dinamis kendaraan yang tereduksi yaitu $\mathrm{m}_{\mathrm{r}}=\mathrm{mt}-1000 \mathrm{~kg}=2265$ $1000=1265 \mathrm{~kg}$.

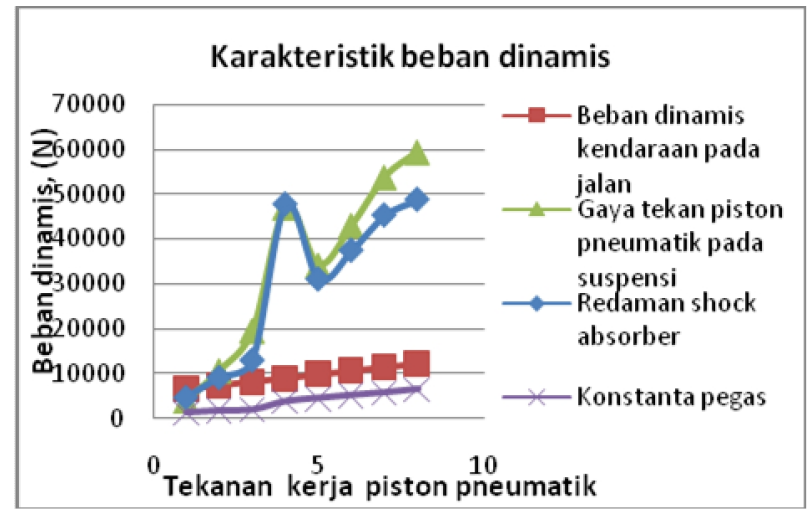

(a)

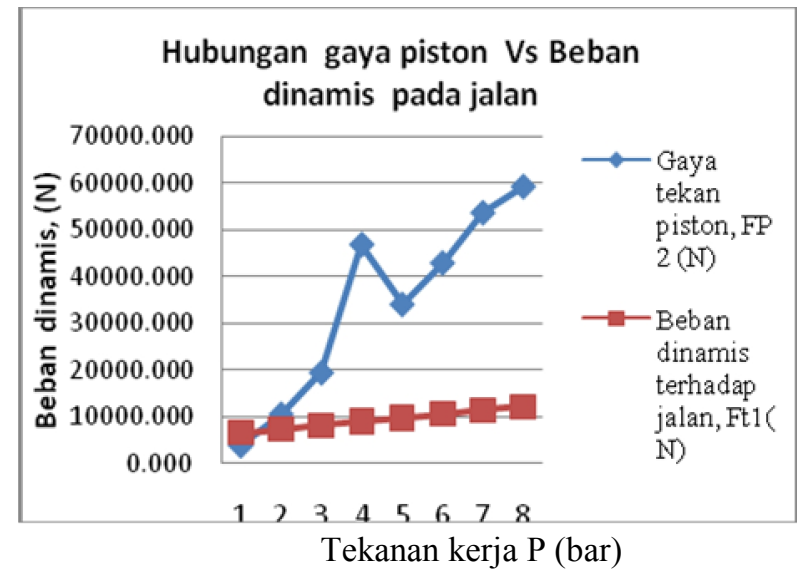

(b)

Gambar 5 (a) Karakteristik beban dinamis oleh gaya piston, $\mathrm{FP}_{2}$ terhadap pegas dan shock absorber. (b) Hubungan antara gaya piston $\mathrm{FP}_{2}$ dan beban dinamis $\mathrm{Ft}_{1}$ yang membebani struktur jalan.

Presentasi penurunan beban dinamis yang membebani struktur jalan oleh adanya redaman dari shock absorber adalah

$$
\frac{2265}{1265} x 100 \%=55.85 \% .
$$

Gambar 6 (a) menunjukkan suatu gambaran yang cukup fantastic bahwa redaman shock absorber yang terpasang pada mekanisme suspensi kendaraan memberikan nilai redaman $\mathbf{c}(\mathbf{N s} / \mathbf{c m})$ terhadap beban dinamis yang sangat besar yaitu berkisar antara $4523.729 \mathrm{Ns} / \mathrm{cm}$ dan $48702.041 \mathrm{Ns} / \mathrm{cm}$. Pengaruh redaman terkecil yang juga digunakan pada sistem suspense kendaraan uji adalah kontribusi redaman pegas ulir $\mathbf{k}_{\mathbf{2}}(\mathbf{N} / \mathbf{c m})$ yang nilainya berkisar antara $1330.508 \mathrm{~N} / \mathrm{cm}$ dan $6408.163 \mathrm{~N} / \mathrm{cm}$. Nilai senjang atau gap yang terjadi antara peredam shock absorber dan pegas ulir, menunjukkan bahwa shock absorber memegang peranan yang sangat besar untuk mereduksi getaran yang ditimbulkan oleh beban dinamis vertikal kendaraan. Gambar 6 (b) menggambarkan karakteristik hubungan antara beban dinamis hasil eksperimen dengan beban dinamis nyata yang terjadi. Dengan menggunakan nilai Koefisien 


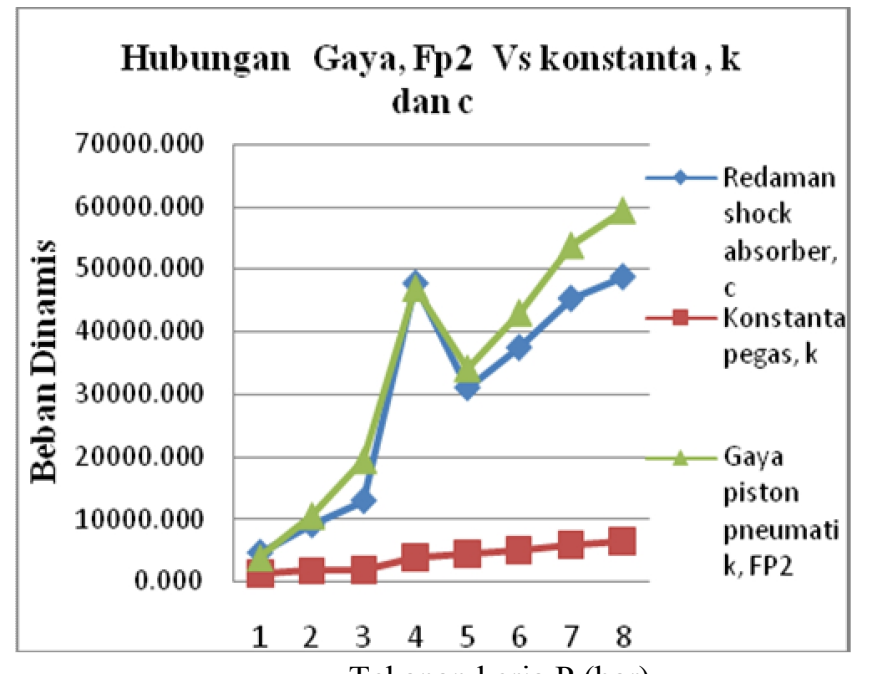

Tekanan kerja P (bar)

( a )

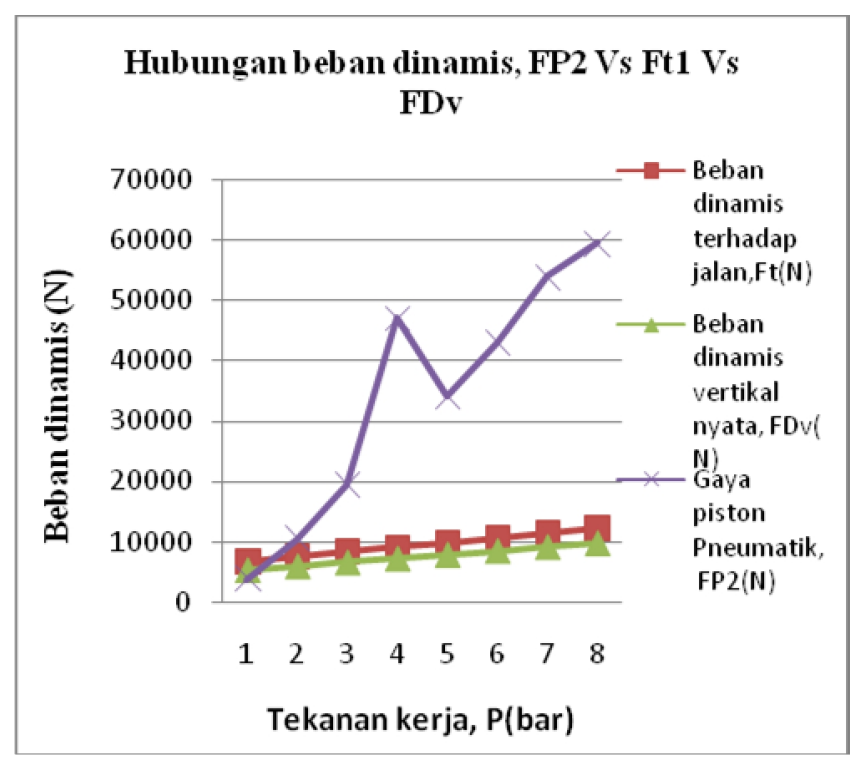

(b)

Gambar 6. (a) Hubungan gaya piston FP2 (N) dengan peredam shock absorber dan pegas ulir (mapershot), (b) Hubungan gaya piston silinder pneumatik $\mathrm{FP}_{2}(\mathrm{~N})$ dengan beban dinamis kendaraan uji $\mathrm{F}_{\mathrm{t}}(\mathrm{N})$ dan Beban dinamis vertikal nyata, FDv (N).

Beban Dinamis, KBD (Dynamic Load Coefficient, DLC) sebesar $20 \%$ yang berlaku untuk kendaraan dengan suspensi hydro-pneumatic maka transformasi beban dinamis vertikal kendaraan yang sesungguhnya adalah mengikuti persamaan (3) dengan nilai kisaran antara $5332(\mathrm{~N})$ dan $9728(\mathrm{~N})$ atau lebih kecil dari nilai bobot $10000(\mathrm{~N})$.

\section{Kesimpulan}

Berdasarkan hasil kajian eksperimen dan pembahasan yang telah dilakukan maka dapat disimpulkan sebagai berikut:

1. Beban dinamis total kendaraan yang dihasilkan dari setiap kendaraan bobot sedang adalah sebesar FDv $=$ 22197 N. Shock Absorber yang terpasang pada mekanisme suspensi kendaraan mampu meredam getaran pada kendaraan sebesar: $55.85 \%$

2. Karakteristik beban lebih $\mathrm{F}(\mathrm{oL})=16204 \mathrm{~N}$ serta beban dinamis berulang sebesar $\mathrm{F}\left({ }_{\mathrm{RL}}\right)=45841 \mathrm{~N}$ selalu akan mempengaruhi kemampuan struktur jalan menerima beban- OL dan beban RL.

3. Hubungan antara beban dinamis dan kekuatan struktur jalan menerima beban yang dinyatakan dalam bentuk parameter tak berdimensi yakni $\mathrm{k}_{\mathrm{dv}}=$ 0.000075 pada sumbu terberat, $\mathrm{k}_{\mathrm{dv}}=0.000103$ untuk beban dinamis total kendaraan serta $\mathrm{k}_{\mathrm{dv}}=0.000213$ untuk beban dinamis berulang.

\section{Ucapan Terima Kasih}

Peneliti ingin menyampaiakan terima kasih yang sebesar-besarnya kepada Direktur Politeknik Negeri Ujung Pandang, dan Menristekdikti yang telah memfasilitasi dan membiayai penelitian ini.

\section{Daftar Pustaka}

[1] A. A. R. Leo Santoso, "Analisis Dampak Beban Overloading Kendaraan pada Struktur Rigid Pavement Terhadap Umur Rencana Perkerasan," Teknik Sipil, vol. 19, p. 8, 2 Agustus 2012.

[2] A. Rehnberg, "Vehicle dynamic analysis of wheel loaders with suspended axles," TRITA-AVE, vol. 15, 2008.

[3] K. Ogata. (1997). Modern Control Engineering (3 ed.).

[4] M. M. Simon Ka'ka, "A method to Compute the Dimension of An Air Distribution Channel of A Pneumatic Cylinder," presented at the IGCESH Conference, Johor Bahru, Malaysia, 2013.

[5] E. Nurcahyanto, "Penggunaan Algoritma GenetikUntuk Perancangan Sistem Suspensi Optimal Pada Model Kendaraan Seperempat," p. 10, 2004.

[6] Yuxin Zhang, Konghui Guo, Dai Wang, Chao Chen, "Energy conversion mechanism and regenerative potential of vehicle suspensions," Energy Conversion and Management, pp. 1-10, 2016.

[7] N. Bangsing, "Pengujian Prototip Suspensi Aktif Tegar (Robust) Model Seperempat Kendaraan," PROC. ITB Sains \& Tek., vol. Vol. 36 A, No. 1,, pp. 83-95, 2004.

[8] Simon Ka'ka, "Kajian Dimensi Saluran Distribusi Udara pada Silinder Pneumatik," S2, Teknik Mesin, Universitas Hasanuddin, Makassar, 2000. 
[9] K. k. Simon, "IbM Pengajar SMK Tri Tunggal 45 dan SMK Handayani untuk Mengembangkan Pembelajaran Pneumatik dan Hidrolik Berbasis Fluid Sim," Prosiding Seminar Nasional Pengabdian Kepada Masyarakat, pp. 122-128, 2017.

[10] Caitrans, "Simulation of a Mobile Crane's Dynamic Load Using the CraneSim Program," The Pavement Research Group, vol. Vol.1 No.1, p. 2, 2005.
[11] Y. klistafani, "Karakteristik Aliran Fluida di Dalam Asymmetric Diffuser dengan Penambahan Vortex Generator," Intek Politeknik Negeri Ujung Pandang, vol. Vol. 5, pp. 22-27, 2018. 